\title{
Measurements and Mesoscale Modeling of Autumnal Vertical Ozone Profiles in Southern Taiwan
}

\author{
Yen-Ping Peng ${ }^{1}$, Kang-Shin Chen ${ }^{1, *}$, Jie-Chung Lou ${ }^{1}$, Shih-Wei Hwang ${ }^{1}$, \\ Wen-Cheng Wang ${ }^{1}$, Chia-Hsiang Lai ${ }^{2}$, and Mong-Yu Tsai ${ }^{3}$ \\ ${ }^{1}$ Institute of Environmental Engineering, National Sun Yat-Sen University, Kaohsiung 80424, Taiwan, ROC \\ ${ }^{2}$ Department of Nursing, Central Taiwan University of Science and Technology, Taichung 40601, Taiwan, ROC \\ ${ }^{3}$ Environmental Protection Bureau, Kaohsiung County 83347, Taiwan, ROC
}

Received 10 April 2007, accepted 4 December 2007

\begin{abstract}
Vertical measurements of ozone were made using a tethered balloon at the Linyuan site in Kaohsiung County, southern Taiwan. Ozone was monitored at altitudes of 0, 100,300, 500, and $1000 \mathrm{~m}$ from November 23 to 25 in 2005. The potential temperature profiles revealed a stable atmosphere during the study period, largely because of the dominance of the high-pressure system and nocturnal radiation cooling close to the surface. The mixing height was low $(50-300 \mathrm{~m})$, particularly in the late night and early morning. The surface ozone concentrations that were predicted using TAPM (The Air Pollution Model) were high (33.7 - 119 ppbv) in the daytime (10:00 - 16:00) and were low (10 $40 \mathrm{ppbv}$ ) at other times; the predictions of which were consistent with the observations. The simulated surface ozone concentrations reveal that costal lands typically had higher ozone concentrations than those inland, because most industrial parks are located in or close to the boundaries of Kaohsiung City. Both measurements and simulations indicate that daytime ozone concentrations decreased quickly with increasing height at altitudes below $300 \mathrm{~m}$; while nighttime ozone concentrations were lower at low altitudes $(50$ to $300 \mathrm{~m}$ ) than at higher altitudes, partly because of dry deposition and titration of surface ozone by the near-surface nitrogen oxides $\left(\mathrm{NO}_{\mathrm{x}}\right)$ and partly because of the existence of the residual layer above the stable nocturnal boundary layer. The simulations show a good correlation between the maximum daytime surface ozone concentration and average nighttime ozone concentration above the nocturnal boundary layer.
\end{abstract}

Key words: Ozone, Tethered balloon, Vertical mixing, Atmospheric modeling, TAPM

Citation: Peng, Y. P., K. S. Chen, J. C. Lou, S. W. Hwang, W. C. Wang, C. H. Lai, and M. Y. Tsai, 2008: Measurements and mesoscale modeling of autumnal vertical ozone profiles in southern Taiwan. Terr. Atmos. Ocean. Sci., 19, 505-514, doi: 10.3319/TAO.2008.19.5.505(A)

\section{INTRODUCTION}

Ground-level ozone $\left(\mathrm{O}_{3}\right)$ is a secondary pollutant, primarily generated from its nitrogen oxides $\left(\mathrm{NO}_{\mathrm{x}}=\mathrm{NO}+\right.$ $\mathrm{NO}_{2}$ ) and $\mathrm{NMHC}$ (non-methane hydrocarbons) precursors in photochemical reactions in sunlight. Although most primary pollutants are emitted in the course of local human activities, high ozone events are also related to the longrange transport of pollutants and meteorological conditions (NRC 1991; Ludwig et al. 1995; Sillman 1999; Blanchard 2000; Russell and Dennis 2000; Trainer et al. 2000).

The transport processes of airborne pollutants include

\footnotetext{
* Corresponding author

E-mail:shin@mail.nsysu.edu.tw
}

the horizontal advection and vertical (downward or upward) movements that are related to small- to large-scale atmospheric motions, meteorological conditions and topography. Vertical measurements suggest that high ozone concentrations aloft during the night may cause pollution events in the following days by downward mixing as the ground heats up and a convective boundary layer develops in the daytime, particularly when a high-pressure system is in the area (Kleinman et al. 1994; Neu et al. 1994; Zhang and Rao 1999; Aneja et al. 2000; Chen et al. 2002; Lin et al. 2004). Unlike the surface measurements of air pollutants, high-altitude measurements are costly and difficult to make. A transport and photochemical model is therefore useful 
and is frequently adopted to develop cost-effective clean air strategies.

Kao-Ping air basin, in southern Taiwan, is heavily industrialized and one of the most polluted regions in Taiwan. In general, high pollution events at Kao-Ping air basin most commonly occur in autumn and/or winter (Chen et al. 2004; Lin et al. 2004). This work measures the autumnal vertical profiles of ozone using a tethered balloon in the Kao-Ping region (Fig. 1). A three-dimensional, mesoscale transport model, called The Air Pollution Model (TAPM; Hurley 2002), was adopted to simulate the temporal and spatial characteristics of ozone during the period of interest.

\section{VERTICAL MEASUREMENTS OF OZONE}

Monitoring for this project was conducted at a roadside monitoring site in Linyuan Township. Linyuan has the largest industrial park (primarily petrol-chemistry) in Kaohsiung County (Fig. 1). Vertical measurements of ozone were made using a tethered-balloon system. The system consisted of a nylon tether line, a helium-filled balloon with a diameter of $3.5 \mathrm{~m}$, tethersonde, sampling bags and an electrical winch to control the ascent and descent of the balloon (Fig. 2). The tethersonde (AIR Model TS-SA-SP) recorded the temperature, pressure, relative humidity, wind speed and wind direction, and transmitted these data to an ADAS (automatic data acquisition system) and a lap-top computer on the ground for storage and analysis. Eight sampling Tedlar bags (SKC No. 232-08) were attached to the tether line to collect gas samples simultaneously at altitudes of 100, 300, 500, and $1000 \mathrm{~m}$ during each flight using an air pump and a synchronized timer. Air samples were collected for at least $10 \mathrm{~min}$ at an airflow rate of $2 \mathrm{~L} \mathrm{~min}^{-1}$. Two identical bags were fastened to the line at each position and were connected to the air pump via an automatic-switching Y-joint. Only one bag of each pair was used, while the other was a standby in case of such accidents as leaking, breaking and/or blowing away of the bag in use.

Since wind speed and balloon buoyancy affected the shape of the tethered line, the data were obtained at height increments of $20 \mathrm{~m}$. The sampling and descent took approximately $45 \mathrm{~min}$. The sounding experiments were performed on four consecutive days, beginning at 03:00 on November 22 and ending at 18:00 on November 25. The balloon was released once every $3 \mathrm{~h}$. The contents of the sampling bags were then analyzed using an ozone analyzer (API Model 400 ), that was based on the absorption principle at the ultra-violent wavelength of $254 \mathrm{~nm}$, with a detection limit of $0.6 \mathrm{ppb}$. The methods used for sampling and analyzing ozone in this work were similar to those described in Chen et

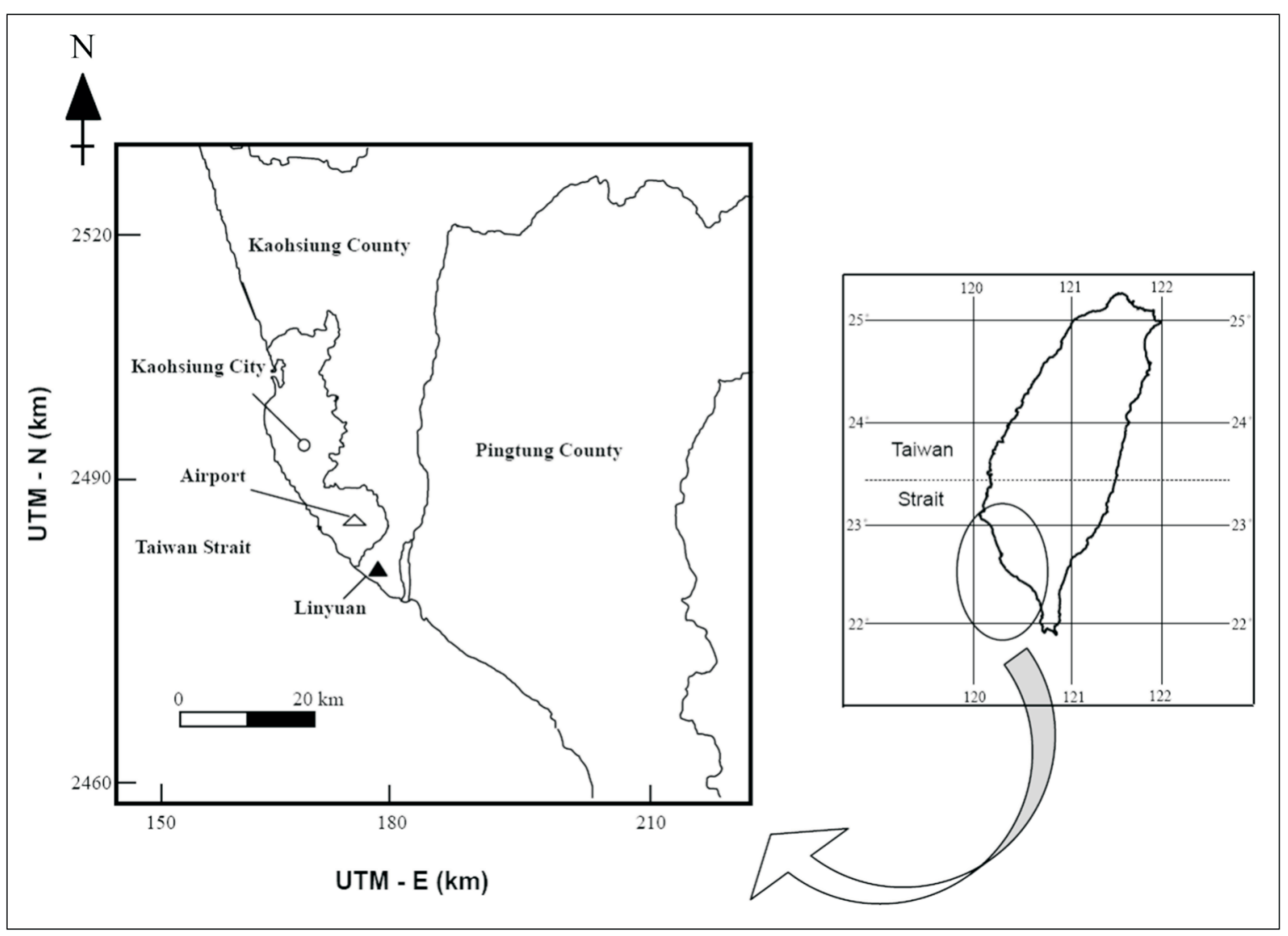

Fig. 1. Map of measurement site (Linyuan) and model domain. 

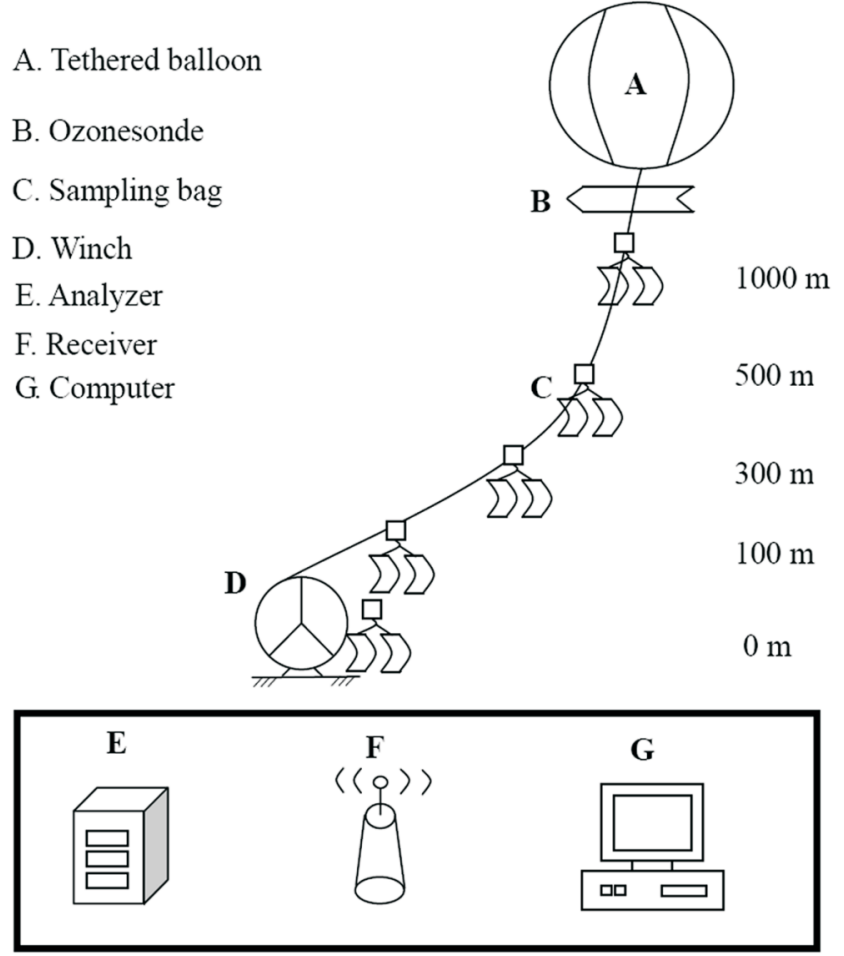

Fig. 2. Tethered balloon with ozonesonde.

al. (2002). A time lag of approximately $0-1 \mathrm{~h}$ occurred between sampling and analysis. The error in ozone concentration due to the adsorption by the sampling bag was estimated to be about $5 \%$, to which all data were corrected. Ozone at the surface was also collected using the sampling bags at the ground level, and then analyzed using the ozone analyzer (API Model 400).

Figure 3 presents the surface weather charts for November 24 and 25 in 2005, indicating that high-pressure systems from China dominated the region. The prevailing wind, on the synoptic scale, was a northeasterly wind over Taiwan, with clear skies and low cloud cover $(<25 \%)$ over southern Taiwan. Notably, when northeasterly winds pass around the Central Mountain Ranges, the downhill winds on the lee (west) side of the Ranges are typically dry and warm, favoring pollutant accumulation and high ozone concentrations. Table 1 presents the surface weather conditions at the Linyuan site, indicating pressures of $1016.1-1016.9 \mathrm{mb}$, wind speeds of $1.9-2.4 \mathrm{~m} \mathrm{~s}^{-1}$, temperatures of $23.1-23.8^{\circ} \mathrm{C}$, and relative humidity of $72.6-76.4 \%$ during the study period.

\section{TAPM MODEL}

\subsection{Governing Equations and Grid Setup}

The Air Pollution Model (TAPM) is a three-dimensional, prognostic, Eulerian, incompressible, non-hydrostatic, primitive equation model in terrain-following vertical coordinates based on nested grids. Hurley (2002) and Hurley et al. (2003) described in details governing equations for mass, momentum, energy, potential temperature and species concentrations, which are briefly elucidated below.

$$
\begin{aligned}
\frac{d u}{d t}= & F(u)+\frac{\partial \overline{w^{\prime} u^{\prime}}}{\partial \sigma} \frac{\partial \sigma}{\partial z}-\theta_{v}\left(\frac{\partial \pi}{\partial x}+\frac{\partial \pi}{\partial \sigma} \frac{\partial \sigma}{\partial x}\right) \\
& +f v-N_{s}\left(u-u_{s}\right)
\end{aligned}
$$

$$
\begin{aligned}
\frac{d v}{d t}= & F(v)+\frac{\partial \overline{w^{\prime} v^{\prime}}}{\partial \sigma} \frac{\partial \sigma}{\partial z}-\theta_{v}\left(\frac{\partial \pi}{\partial y}+\frac{\partial \pi}{\partial \sigma} \frac{\partial \sigma}{\partial y}\right) \\
& +f u-N_{s}\left(v-v_{s}\right)
\end{aligned}
$$

$$
\frac{\partial \dot{\sigma}}{\partial \sigma}=-\left(\frac{\partial u}{\partial x}+\frac{\partial v}{\partial y}\right)+u \frac{\partial}{\partial \sigma}\left(\frac{\partial \sigma}{\partial x}\right)+v \frac{\partial}{\partial \sigma}\left(\frac{\partial \sigma}{\partial y}\right)
$$
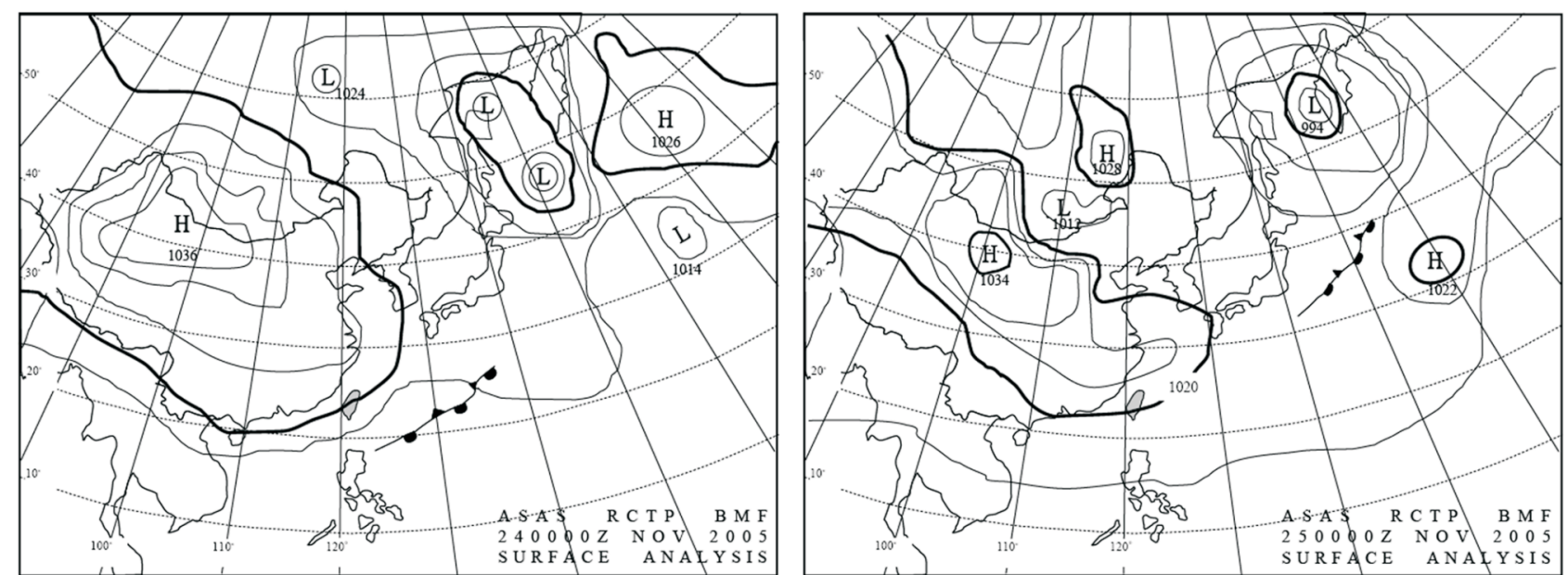

Fig. 3. Surface weather charts on 24 and 25 November 2005. 
Table 1. Average weather conditions at the Linyuan site on 23 to 25 November 2005.

\begin{tabular}{cccc}
\hline Date & Temperature $\left({ }^{\circ} \mathbf{C}\right)$ & Wind speed $\left(\mathbf{m ~ s}^{-1}\right)$ & Wind direction \\
\hline $23 / 11 / 2005$ & 23.6 & 2.4 & NNE \\
$24 / 11 / 2005$ & 23.1 & 1.9 & NNW \\
$25 / 11 / 2005$ & 23.8 & 1.9 & NNW \\
\hline Date & Relative Humidity (\%) & Period of sunshine (h) & Pressure (mb) \\
\hline $23 / 11 / 2005$ & 75.0 & 9.6 & 1016.9 \\
$24 / 11 / 2005$ & 76.4 & 8.6 & 1016.3 \\
$25 / 11 / 2005$ & 72.6 & 9.2 & 1016.1 \\
\hline
\end{tabular}

$\frac{d \theta_{v}}{d t}=F\left(\theta_{v}\right)+\frac{\partial \overline{w^{\prime} \theta_{v}^{\prime}}}{\partial \sigma} \frac{\partial \sigma}{\partial z}+S_{\theta_{v}}-N_{s}\left(\theta_{v}-\theta_{v S}\right)$

$\frac{d}{d t}=\frac{\partial}{\partial t}+(u, v) \cdot \nabla$ and $\sigma=z_{T}\left(\frac{z-z_{s}}{z_{T}-z_{s}}\right)$

In the above, $t$ is the time; $z_{T}$ is the height of the top of the model and $z_{s}$ is the height of the terrain; $\sigma$ is the sigma-pressure; $(u, v)$ refers to the horizontal winds; $\dot{\sigma}$ refers to the vertical wind; $u_{s}$ and $v_{s}$ refer to large-scale synoptic winds; $\overline{w^{\prime} \phi^{\prime}}$ is the eddy term; $f$ is the Coriolis parameter; and $\theta_{v}$ is the potential virtual temperature. The turbulence terms in Eqs. (1) and (2) are determined by solving equations for the turbulent kinetic energy and the eddy dissipation rate. The governing equations for species concentrations $(\chi)$, such as those of $\mathrm{O}_{3}$, $\mathrm{NO}_{2}$, and $\mathrm{SO}_{2}$, are:

$$
\begin{aligned}
\frac{d \chi}{d t}= & \frac{\partial}{\partial x}\left(K_{\chi} \frac{\partial \chi}{\partial x}\right)+\frac{\partial}{\partial y}\left(K_{\chi} \frac{\partial \chi}{\partial y}\right) \\
& -\left(\frac{\partial \sigma}{\partial z}\right) \frac{\partial}{\partial \sigma}\left(\overline{w^{\prime} \chi^{\prime}}\right)+R_{\chi}+S_{\chi}
\end{aligned}
$$

where $K_{\chi}$ is the diffusion coefficient; $\overline{w^{\prime} \chi^{\prime}}$ is the eddy term; $R_{\chi}$ is the chemical reaction term, and $S_{\chi}$ is the pollutant emission term. The diffusion coefficient used for pollutant concentration is $K_{\chi}=2.5 \mathrm{~K}$, where $K$ is the diffusion coefficient for the turbulent kinetic energy. Furthermore, 13 species are involved in ten reactions. These are $\mathrm{NO}, \mathrm{NO}_{2}, \mathrm{O}_{3}$, and $\mathrm{SO}_{2}$, hydrogen peroxide $\left(\mathrm{H}_{2} \mathrm{O}_{2}\right), \mathrm{R}_{\text {smog }}$, radical pool (RP), stable non-gaseous organic carbon (SNGOC), stable gaseous nitrogen products (SGN), stable non-gaseous nitrogen products (SNGN), stable nongaseous sulfur products (SNGS), Airborne Particulate Matter (APM), and Fine Particulate Matter (FPM) that include secondary particulate concentrations of (SNGOC), (SNGN), and (SNGS). Hurley (2002) presented pertinent details. In this work, the emission rates of pollutants were considered by inputting them via boundary conditions, as will be discussed in the following section.

The TAPM is run on a personal computer to simulate mesoscale atmospheric motions with meteorological, geographical and air pollution components. The TAPM uses the nested grids to do the simulation. Five square grids were nested on each horizontal layer, with sizes of (from the outside to the inside): $30,10,3,1$, and $0.3 \mathrm{~km}$. The domain of the coarse outer grid covered over $500 \times 500 \mathrm{~km}$ (the smaller plot on the right of Fig. 1), while the fine inner grids covered southern Taiwan (the larger plot on the left of Fig. 1), with a north-south length of $75 \mathrm{~km}$ and a west-east width of $75 \mathrm{~km}$ in the 1-m grid. The Linyuan site, marked by a dark triangle in Fig. 1, was overlaid with the finest grid with cells of $0.3 \mathrm{~km}$. The vertical domain was $8000 \mathrm{~m}$ high and comprised 22 horizontal layers at altitudes of 10, 25, 50, $100,150,200,250,300,400,500,600,750,1000,1250$, $1500,1750,2000,2500,3000,3500,4000$, and $5000 \mathrm{~m}$.

\subsection{Emission Inventory and Boundary Conditions}

An emission inventory was obtained using TEDS-6.03 (Taiwan Emission Data System), issued by Taiwan-EPA (Environmental Protection Administration) in 2006. Table 2 presents all the emission rates of $\mathrm{SO}_{\mathrm{x}}$ (sulfur dioxides), $\mathrm{NO}_{\mathrm{x}}$ and NMHC from the stationary and mobile sources in each region. The methods of obtaining emission rates from various sources, except the updated emission rates in TEDS6.03, were similar to those in TEDS-4.2, issued by Taiwan-EPA in 1997 (Chen et al. 2003). However, reactive hydrocarbons, $R_{\text {smog, }}$, replace the NMHC rate in the TAPM, in which $\mathrm{R}_{\text {smog }}$ is defined as the product of a reactive coefficient (or a multiplicative factor) and NMHC emissions. Given the potential uncertainty in the emission inventory, tests were performed to optimize the simulations; multiplicative factors of $0.025,0.023$, and 1.0 were applied to the emission rates of $\mathrm{NMHC}, \mathrm{NO}_{\mathrm{x}}$, and $\mathrm{SO}_{\mathrm{x}}$, respectively, in this work.

TAPM classifies the surface vegetation (land-use) into 29 classes. Surface data in the model domain were obtained 
Table 2. Emissions in ton per year from TEDS-6.03 (2006).

\begin{tabular}{rrrcccrr}
\hline & & Jia-Yi Area & Tainan Aera & Kaohsiung County & Kaohsiung City & Ping-Tung Area & Total \\
\hline \multirow{2}{*}{ Stationary } & $\mathrm{SO}_{\mathrm{x}}$ & 2643 & 11445 & 20124 & 39353 & 1409 & 74974 \\
Source & $\mathrm{NO}_{\mathrm{x}}$ & 6507 & 10821 & 38530 & 56501 & 3673 & 116032 \\
& $\mathrm{NMHC}$ & 30007 & 51466 & 53086 & 44961 & 14273 & 193793 \\
$\cdots$ & $\mathrm{SO}_{\mathrm{x}}$ & 721 & 653 & 497 & 4158 & 371 & 6400 \\
\multirow{2}{*}{ Mobile } & $\mathrm{NO}_{\mathrm{x}}$ & 16796 & 32103 & 23402 & 29640 & 12577 & 114518 \\
Source & $\mathrm{NMHC}^{*}$ & 9485 & 22858 & 15385 & 20637 & 10342 & 78707 \\
\hline
\end{tabular}

using geographical charts that were issued by the Ministry of the Interior of the Taiwan Government, to determine the area fractions of the land-use in each grid cell. The TAPM model is initialized at each grid point with values of wind velocities, temperatures, and humidity ratios that were interpolated from synoptic analyses. At the top of the model, all variables were set to their synoptic values. Four-dimensional data assimilation (FDDA) was adopted to compare simulated surface winds with ground observations and to correct the horizontal momentum equations using the Newtonian relaxation (or nudging) procedure (Stauffer and Seaman 1994; Hurley 2002).

In the TAPM model, the initial concentrations of pollutants at the inflow boundaries on the outermost grids are set to background values, while zero-gradient conditions are applied at the outflow boundaries. The background concentrations of species on the outermost grids remain invariant throughout the simulation. Once the initial and outermost boundary conditions are set, the TAPM model solves the concentrations of pollutants on the fine inner grids. Since all simulations began at midnight (00:00), at which time ozone concentration is very low and close to $10 \mathrm{ppbv}$ in southern Taiwan, the background value of ozone was thus set to $10 \mathrm{ppbv}$ in all simulations herein. The background conditions for other species were set to $0.7 \mathrm{ppbv}$ for $\mathrm{R}_{\text {smog }}$ (Hurley et al. 2003), 1 ppbv for $\mathrm{SO}_{2}$ and 3 ppbv for $\mathrm{NO}_{2}$ (Chang and Cardelino 2000). Notably, the initial values of the eddy terms were set to zero because of thermally stable conditions at midnight.

The performance of the model was obtained relative to the actual measurements using the correlation coefficient $(R)$ and the index of agreement (IOA) using (Willmott et al. 1985)

$$
\mathrm{IOA}=1-\frac{\sum_{i=1}^{N}\left(\left|P_{i}-O_{i}\right|\right)^{2}}{\sum_{i=1}^{N}\left(\left|P_{i}-\bar{O}\right|+\left|O_{i}-\bar{O}\right|\right)^{2}}
$$

where $P_{i}$ and $O_{i}$ are the predicted and measured values, respectively, with a sample size $N$, and $\bar{O}$ is the average over all measured data. The agreement between prediction and measurement is regarded as good when IOA exceeds 0.5 (Hurley et al. 2001, 2003).

\section{RESULTS AND DISCUSSION}

\subsection{Measured Meteorological Parameters and Vertical Ozone Profiles}

Figure 4 presents the measured time-height wind vectors on November 23 to 25 in 2005. Generally, the north to north-easterly winds prevailed, accompanying wind shifts in

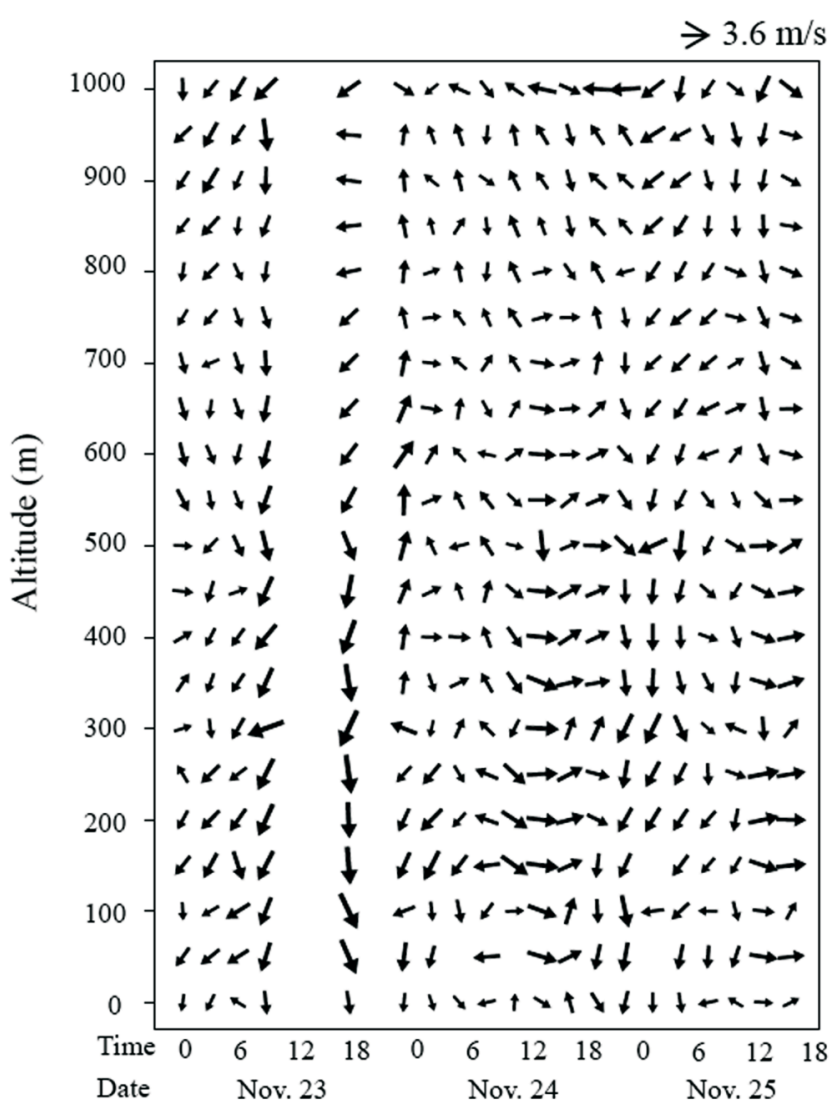

Fig. 4. Time-height measured horizontal velocity vectors at Linyuan site from November 23 to 25 in 2005 . 
each layer. For instance, surface winds shifted from westnorth at 06:00 to east at 09:00 on November 24, and from south-east at 12:00 to west at 15:00 on November 25 (see Fig. 7 also). Wind speeds increased from $0.1-2.2 \mathrm{~m} \mathrm{~s}^{-1}$ at the surface to about $7.2 \mathrm{~m} \mathrm{~s}^{-1}$ at an altitude of $200-300 \mathrm{~m}$, and then decreased slowly with height. Wind data were unavailable at 15:00 and at 21:00 on November 23 because measurements failed.

Figure 5 plots the measured potential temperature versus height at selected times, indicating a stable atmosphere, because of the dominance of a high pressure system and nocturnal radiation cooling near the surface. The mixing height was low $(50-300 \mathrm{~m})$, particularly in the late night and early morning. Chen et al. (2004) reported that the maximum mean mixing height was about $850 \mathrm{~m}$, whereas the minimum mean was $50-400 \mathrm{~m}$ in the autumn.

Figure 6 presents the measured time-height ozone contours for the three consecutive days. The plot clearly reveals that the surface ozone concentration was only high (45 119 ppbv) during the daytime (09:00 - 16:00). Furthermore, daytime ozone concentrations at low altitudes exceeded those above $100 \mathrm{~m}$. In contrast, although they were low during the nighttime, ozone concentrations (16.8 - $42.3 \mathrm{ppbv})$ at high altitudes $(100-1000 \mathrm{~m})$ exceeded those $(14.2$ $29.6 \mathrm{ppbv}$ ) at low altitudes. This result is explained by the fact that nocturnal radiation cooling yields a low and stable boundary layer and reduces the vertical mixing of pollutants. Additionally, in the absence of sunlight, low-altitude ozone is more easily depleted by the dry deposition and titration of $\mathrm{NO}_{\mathrm{x}}$ than is high-altitude ozone. This result supports the notion that high nighttime ozone levels aloft can result in high

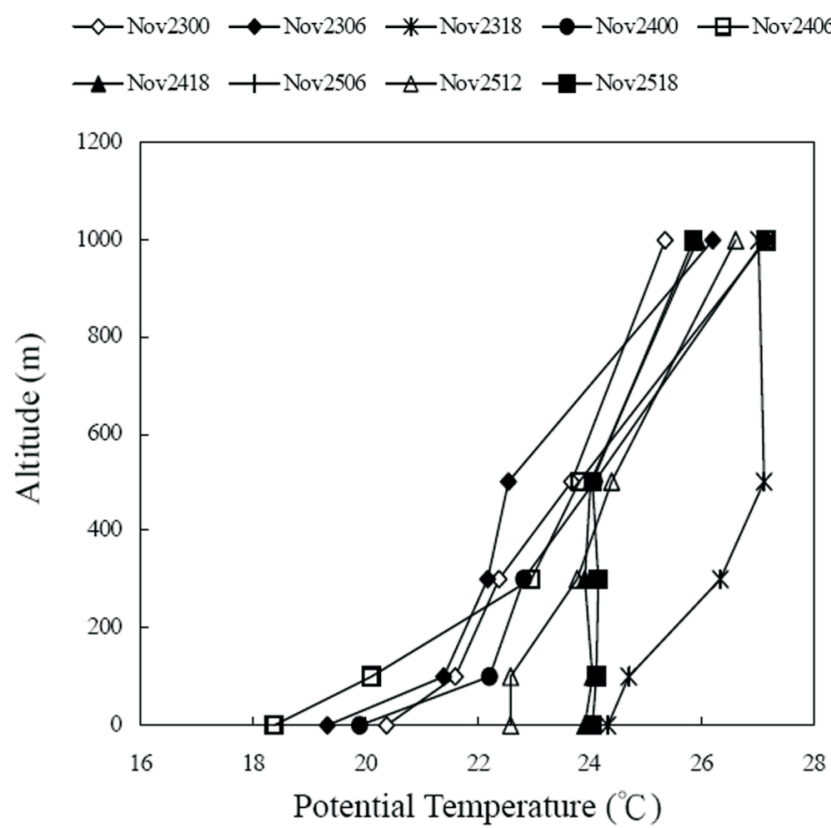

Fig. 5. Variations of potential temperature with height at selected times at Linyuan site from November 23 to 25 in 2005. pollutant events in the following day when the surface heats up and vertical mixing develops (Zhang and Rao 1999; Aneja et al. 2000; Chen et al. 2002; Salmond and Mckendry 2002; Lin et al. 2004), although other complexities may prevail, including low-level jet, advection and topography (Salmond and Mckendry 2002).

\subsection{Comparisons between Predicted and Measured Ozone Concentrations}

Figure 7a presents the simulated surface-wind vectors and concentration contours of ozone at 10:00 and 14:00 on 24 November 2005, respectively. The solid triangle in the plots marks the Linyuan site and the contours represent the elevations of the mountain (on the right), with a highest elevation of approximately $2957 \mathrm{~m}$. In Fig. 7a, the onshore winds from the northwest blew west inland at speeds of 0.9 $3.4 \mathrm{~m} \mathrm{~s}^{-1}$, and then merged with downhill winds near the foot of the mountain. This result is consistent with the surface weather charts that are presented in Fig. 3, in which the prevailing wind, on the synoptic scale, was the northeasterly wind over Taiwan, as discussed earlier. Northeasterly winds are blocked by the Central Mountain Ranges and split into two currents, which pass around the ranges to the north and south (Lin 2001), indicating that these winds were dominated by large-scale synoptic winds rather than by thermally-driven circulations. The concentration contours in Fig. 7a reveal that ozone concentrations (55 - $88 \mathrm{ppb})$ were high close to the costal lands, where most industrial parks are located, but were low (35 - 45 ppbv) inland, which is mostly rural and mountainous. The pattern of simulated surface winds in Fig. 7b, except for relatively high speeds, was similar to that in Fig. 7a. However, the afternoon ozone levels in Fig. 7b, about 65 - 95 ppbv near the coastal lands and 35 - 55 ppbv in other regions, exceeded those at noon because the photochemical reaction of ozone precursors

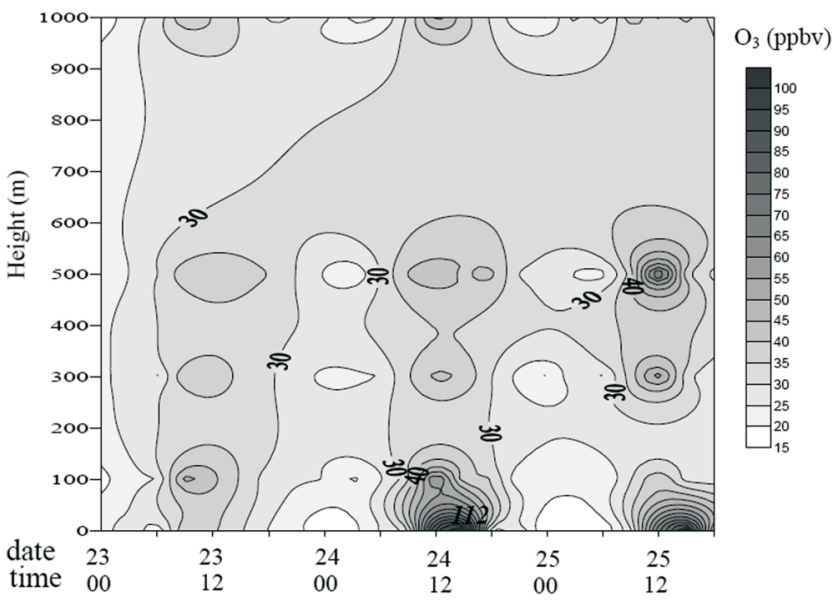

Fig. 6. Time-height contours of measured zone concentration (ppb) at Linyuan site on November 23 to 25 in 2005. 
(a) 10:00

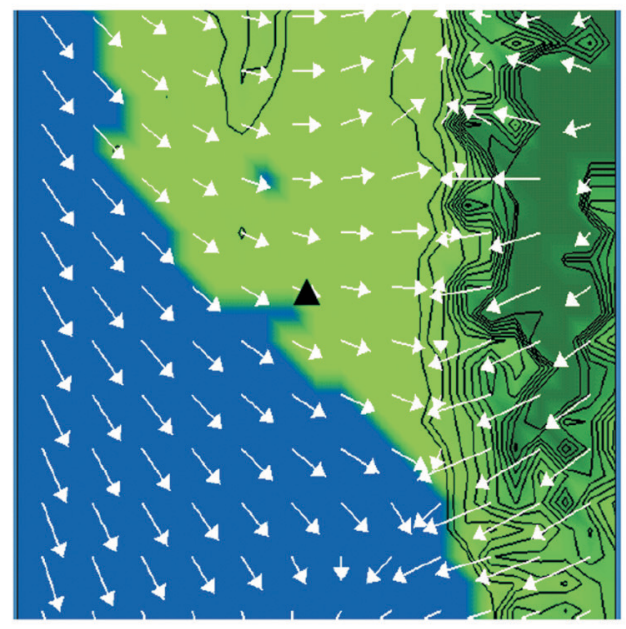

$\boldsymbol{\Delta}:$ Linyuan

(b) $14: 00$

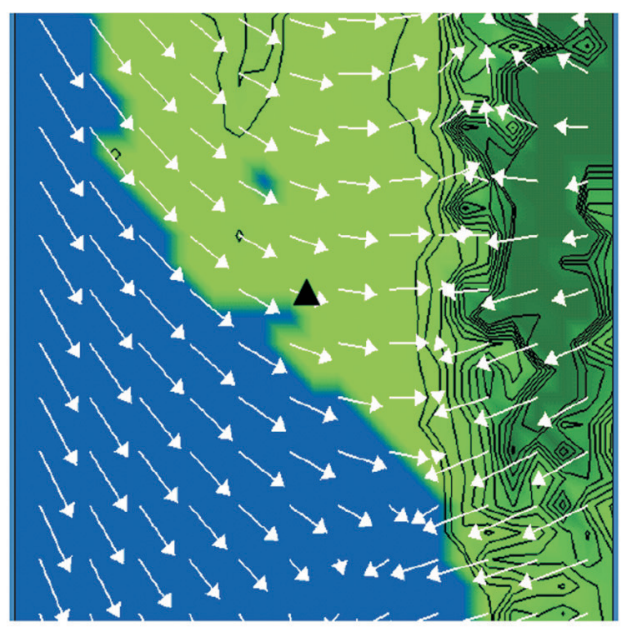

$\boldsymbol{\Delta}:$ Linyuan

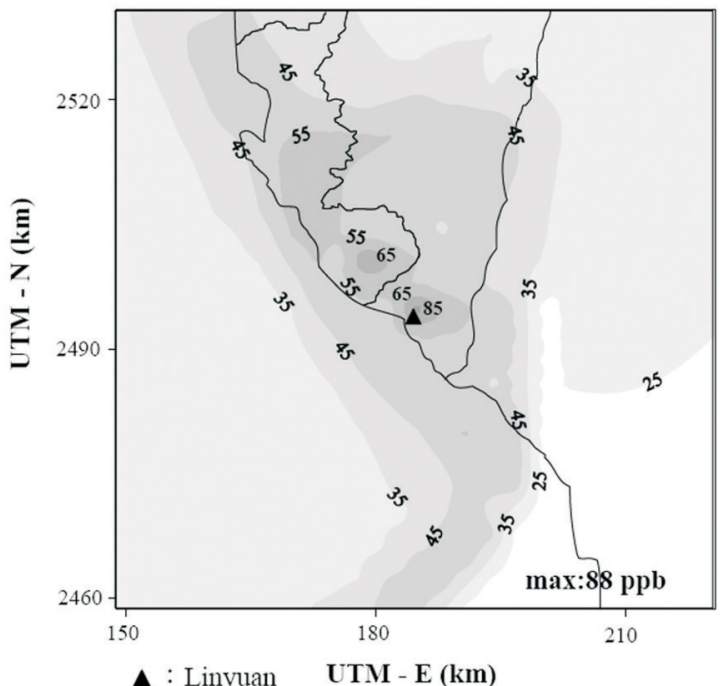

$\Delta$ : Linyuan UTM - E $(\mathrm{km})$

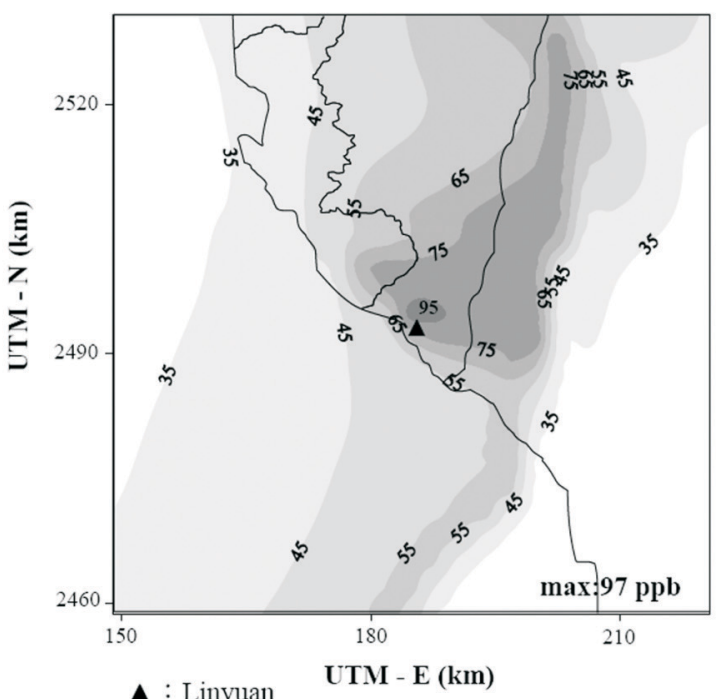

Fig. 7. Simulated surface wind vectors and ozone concentration contours (ppb) on November 24 in 2005 at: (a) 10:00, and (b) 14:00.

continued from noon to the afternoon.

Figure 8 compares the three-day hourly simulations of surface ozone concentrations with the measurements at the Linyuan site. The plots reveal that the concentrations of surface ozone began to rise at 08:00 to 09:00 in the morning; peaked at noon to afternoon (13:00 to 16:00), and decreased thereafter, remaining low from the night to the early morning. The highest measured ozone concentrations were $80 \mathrm{ppbv}$ at 13:00 on November 23, 119 ppbv at 14:00 on November 24, and $111 \mathrm{ppbv}$ at 14:00 on November 25; the latter two values were just below the hourly standard of $120 \mathrm{ppbv}$. These high ozone events were closely related to the high pressure systems on these days. Although the predicted concentrations were higher than the measurements from the morning to noon on the second and third days, the

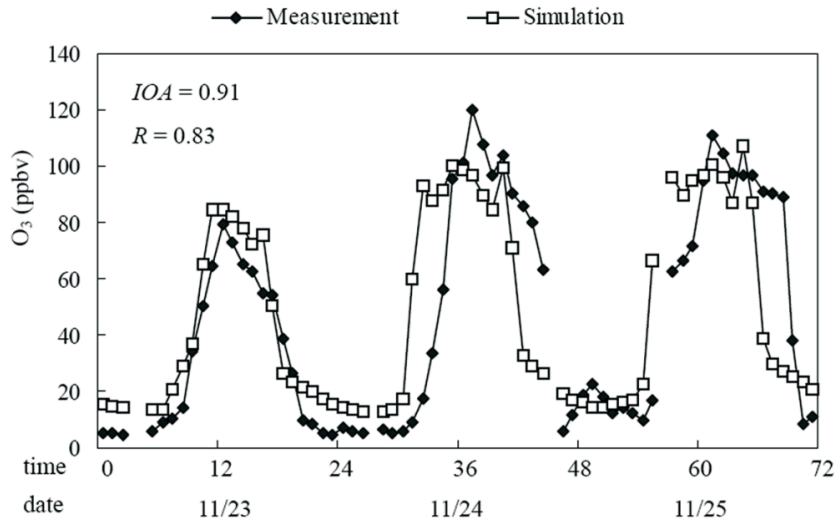

Fig. 8. Comparisons of hourly surface ozone concentrations at Linyuan site from November 23 to 25 in 2005. 
simulations generally agreed well with the measurements, with a correlation coefficient of $R=0.83$ (strong correlation), and an index of agreement of IOA $=0.91$.

Figure 9a plots the measured and predicted variations of ozone concentration vs. height at various times (09:00, 12:00, and 15:00) on November 24 and November 25. Both measurements and predictions indicated that ozone levels decreased quickly as the altitude increased below about $300 \mathrm{~m}$ at 12:00 on November 24 and below about $50 \mathrm{~m}$ at 15:00 on November 25; ozone concentrations varied insignificantly - by less than 10 ppbv - above 300 or $50 \mathrm{~m}$. However, decreasing ozone concentration with altitude was less marked at 09:00 than at 12:00 and 15:00, mainly because vertical mixing processes at noon and in the afternoon were much stronger than those in the morning. Therefore, ozone concentrations decreased more quickly with increasing altitude at noon and in the afternoon than in the morning. Figure $9 \mathrm{~b}$ plots the measured and predicted variations of ozone concentrations with height at selected times at night (00:00) and in the early morning (06:00). Ozone concentrations at high altitudes were low at midnight and in the early morning. Both measurements and predictions indicated that ozone levels increased with increasing altitude at $50-300 \mathrm{~m}$ and varied little above $300 \mathrm{~m}$. These outcomes are consistent with the previous results. In Fig. 9b, the ozone concentrations ( 15 - $30 \mathrm{ppbv}$ ) above 100 m exceeded those on the ground (14 - $20 \mathrm{ppbv}$ ), mainly because radiation cooling yielded a low and stable nocturnal boundary layer (NBL), above which a relatively high ozone concentration was present in the residual layer.

Although simulations agreed well with measurements of the surface ozone concentrations, they differed significantly for the ozone concentrations aloft; in particular, the discrepancies between ozone levels were larger in the daytime (Fig. 9a) than in the nighttime (Fig. 9b). Apart from the uncertainty associated with the emission inventory in the model and measurement errors, the large discrepancies in the daytime may be caused by the relatively large variations of winds aloft during the daytime. For instance, the wind speeds aloft varied between 0.4 and $7.2 \mathrm{~m} \mathrm{~s}^{-1}$ in the daytime, but varied between 0.4 and $5.0 \mathrm{~m} \mathrm{~s}^{-1}$ in the nighttime (Fig. 4). Since the TAPM model used the FDDA approach to correct for surface winds and not winds aloft simulations were closer for the surface ozone concentrations than for the ozone concentrations aloft.

\subsection{Downward Mixing Effect}

Earlier studies have demonstrated that the daytime ozone concentration close to the ground may be affected by the previous night's ozone concentration above the NBL because downward mixing occurs as the mixing layer begins to develop in the early morning (Kleinman et al. 1994; Neu et al. 1994; Zhang and Rao 1999; Aneja et al.
2000; Chen et al. 2002; Lin et al. 2004). Figures 10a and b present the vertical profiles of potential temperature and ozone concentration at the Linyuan site at midnight (00:00) and noon (12:00) on 24 November, respectively. An NBL was present below approximately $300 \mathrm{~m}$, with an inversion layer below $100 \mathrm{~m}$ at midnight (Fig. 10a), which disfavored vertical mixings; therefore, low-level ozone concentrations increased with increasing altitude at low altitudes (Fig. 10b). However, an unstable layer was present at low altitudes below $300 \mathrm{~m}$ at noon (Fig. 10a), favoring vertical mixing; therefore, low-level ozone concentration decreased as the altitude increased below $300 \mathrm{~m}$ (Fig. $10 \mathrm{~b}$ ). The nighttime surface ozone concentration was very low, mainly because no sunlight was available to produce ozone and because ozone removal processes, such as surface deposition and the destruction of ozone with nitric oxide (such as $\mathrm{O}_{3}+\mathrm{NO} \rightarrow \mathrm{O}_{2}+\mathrm{NO}_{2}$ ), occurred. Figure $10(\mathrm{~b})$ clearly indicates that vertical daytime ozone concentrations exceeded those at nighttime. Therefore, the increase in daytime ozone concentration was caused partially by the photochemical reaction of ozone precursors and partially by the downward mixing of the ozone after the boundary layer

(a)

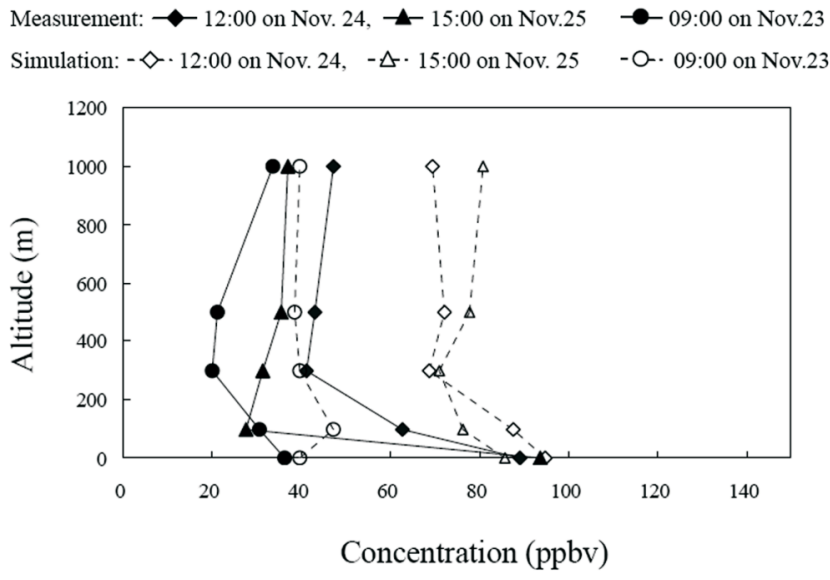

(b)

Measurement: $-\mathbf{- 0 0 : 0 0}$ on Nov. $24,-06: 00$ on Nov.23 - - 00:00 on Nov. 25 Simulation: $-\square \cdot 00: 00$ on Nov. $24,-0 \cdot 06: 00$ on Nov. $23-\Delta \cdot 00: 00$ on Nov. 25

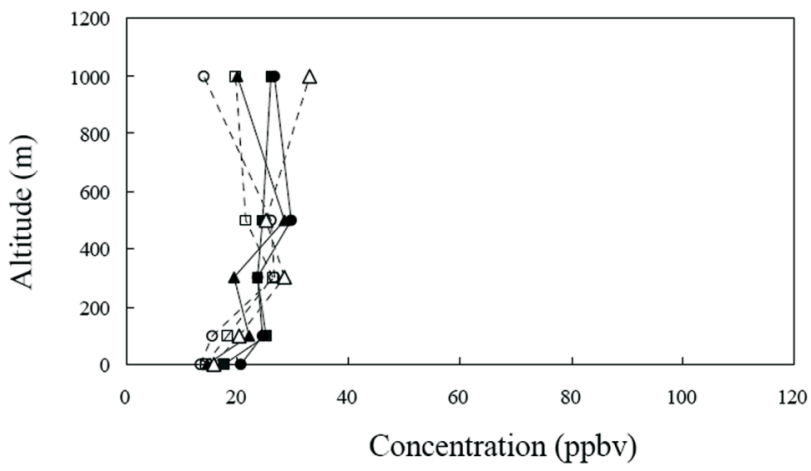

Fig. 9. Comparisons of vertical ozone profiles at Linyuan site at selected times: (a) in the daytime; and (b) in the nighttime and morning. 

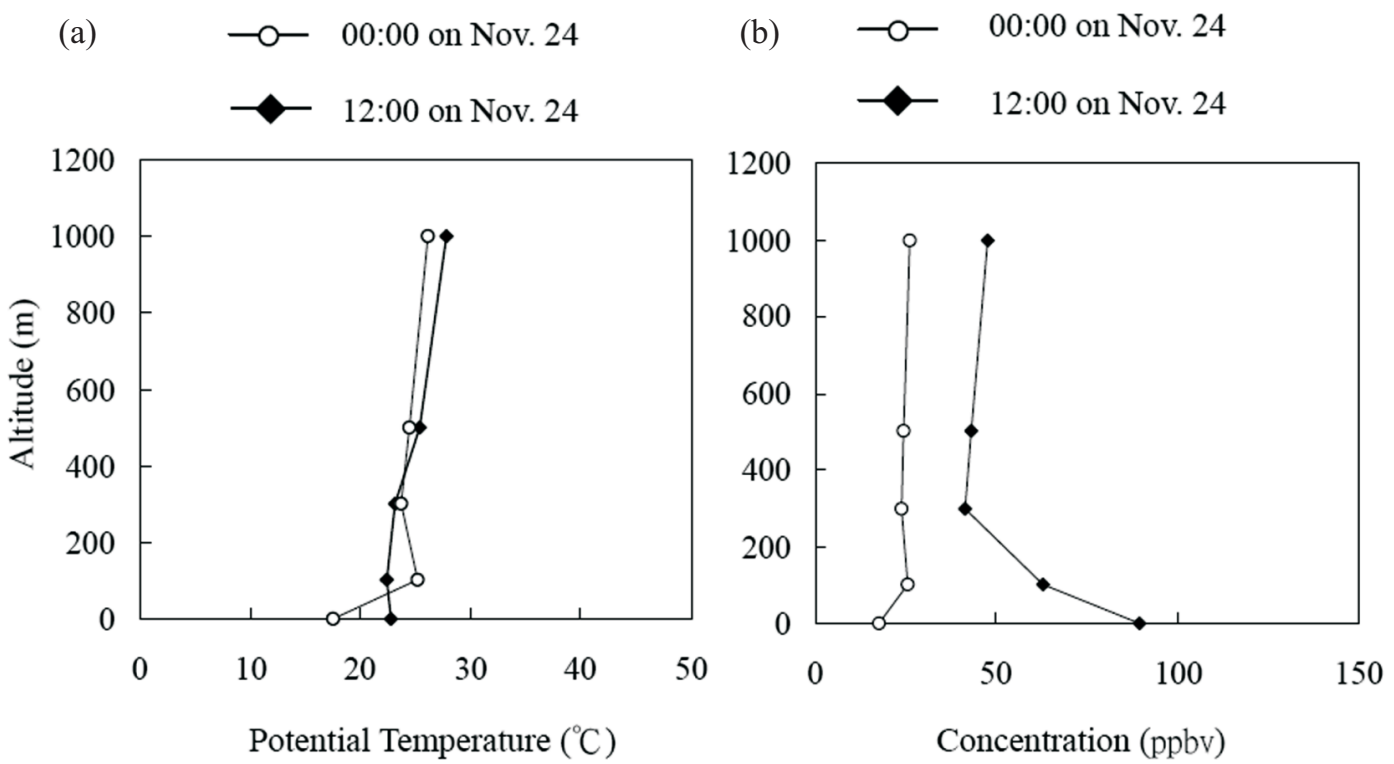

Fig. 10. Vertical profiles of: (a) potential temperature and (b) ozone concentration at Linyuan at midnight (00:00) and at noon (12:00) on 24 November 2005 .

grew during the middle of the previous night. The data of Lin et al. (2004) indicated that downward mixing as the early morning boundary layer developed increased the ozone concentration by about 18 ppbv. Simulations by Zhang and Rao (1999) indicated that the vertical mixing process in the morning dictates the overall ozone concentration. Both vertical mixing and chemical production processes control the surface ozone concentration at noon and in the afternoon, during which the vertical mixing tends to dilute the ozone concentration, while the photo-chemical process produces ozone by reactions of its precursors (Zhang and Rao 1999).

Aneja et al. (2000) and Chen et al. (2002) developed empirical relationships between the daytime maximum $\mathrm{O}_{3}$ concentration at the surface and the previous night's average $\mathrm{O}_{3}$ concentration above the $\operatorname{NBL}(R=0.6-0.7$ in the two works). Similarly, a simulation of 12 days in November 2005 was performed to study the effects of downward mixing on ozone concentrations. Figure 11 indicates that the average ozone concentrations $\left(\bar{C}_{N B L}\right)$ from midnight to early morning (00:00 to $06: 00)$ above the NBL correlated fairly well $(R=0.64)$ with maximum surface ozone concentrations $\left(C_{\text {omax }}\right)$ in the daytime (09:00 to $\left.15: 00\right)$.

\section{CONCLUSIONS}

Vertical ozone profiles were made using a tethered balloon at the Linyuan site in Kaohsiung County from November 23 to 25 in 2005. Ozone was monitored at heights of $0,100,300,500$, and $1000 \mathrm{~m}$. High ozone events were closely related to the dominance of a high pressure system, yielding a stable atmosphere and low mixing height. The surface ozone concentrations predicted using TAPM (The Air Pollution Model) were high (33.7 - $119 \mathrm{ppbv})$ during the day (10:00 16:00) and low (10 - $40 \mathrm{ppbv})$ at other times, which results were consistent with the observations. Both measured and simulated results indicated that daytime ozone levels decreased rapidly as height increased at altitudes below $300 \mathrm{~m}$, while nighttime ozone concentrations (16.8 - $42.3 \mathrm{ppbv})$ at high altitudes $(100-1000 \mathrm{~m})$ exceeded those $(14.2$ $29.6 \mathrm{ppbv})$ at low altitudes $(\leq 100 \mathrm{~m})$, partly due to dry deposition and the depletion of surface ozone by $\mathrm{NO}_{\mathrm{x}}$ close to the ground and partly due to the existence of the residual

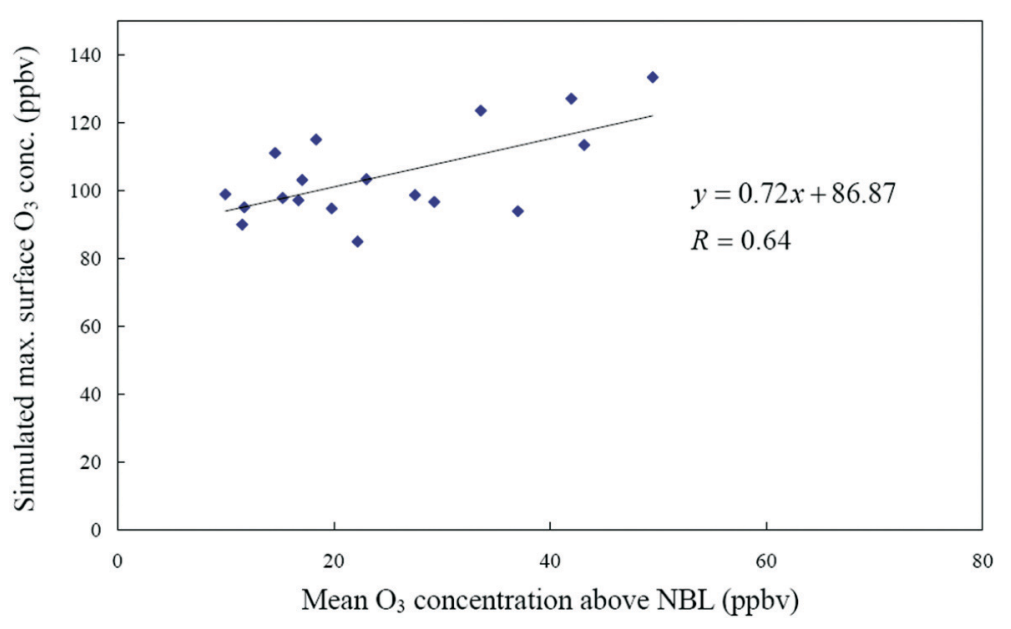

Fig. 11. Simulated relationship between average $\mathrm{O}_{3}$ concentration at elevated levels above $500 \mathrm{~m}(00$ - $06 \mathrm{LT})$ and maximum daytime surface ozone concentration (09 15 LT) at Linyuan, southern Taiwan in November 2005. 
layer above the nocturnal boundary layer. Although some notable discrepancies existed between simulations and measurements, they were fairly consistent, particularly in the spatial and temporal variations of ozone profiles.

Acknowledgements This work was supported by the Environmental Protection Bureau, Government of Kaohsiung County, Taiwan. The authors would like to thank graduate students C. M. Pan, C. E. Huang, and C. H. Lin for their assistance during the course of field measurements. Ted Knoy is appreciated for his editorial assistance.

\section{REFERENCES}

Aneja, V. P., R. Mathur, S. P. Arya, Y. Li, G. C. Murray Jr., and T. L. Manuszak, 2000: Coupling the vertical distribution of ozone in the atmospheric boundary layer. Environ. Sci. Technol., 34, 2324-2329.

Blanchard, C. L., 2000: Ozone process insights from field experiments - Part III: Extent of reaction and ozone formation. Atmos. Environ., 34, 2035-2043.

Chang, M. E. and C. Cardelino, 2000: Application of the urban airshed model to forecasting next-day peak ozone concentrations in Atlanta, Georgia. J. Air Waste Manage. Assoc., 50, 2010-2024.

Chen, C. L., B. J. Tsuang, C. Y. Tu, W. L. Cheng, and M. D. Lin, 2002: Wintertime vertical profiles of air pollutants over a suburban area in central Taiwan. Atmos. Environ., 36, 2049-2059.

Chen, K. S., Y. T. Ho, C. H. Lai, and Y. M. Chou, 2003: Photochemical modeling and analysis of meteorological parameters during ozone episodes in Kaohsiung, Taiwan. Atmos. Environ., 37, 1811-1823.

Chen, K. S., Y. T. Ho, C. H. Lai, Y. A. Tsai, and S. J. Chen, 2004: Trends in concentrations of ground-level ozone and meteorological conditions during high ozone episodes in the Kao-Ping Airshed, Taiwan. J. Air Waste Manage. Assoc., 54, 36-48.

Hurley, P., 2002: The Air Pollution Model (TAPM) Version 2. Part 1: Technical Description. CSIRO Atmospheric Research, Aspendale, Vic 3195, Australia.

Hurley, P., P. Manins, S. Lee, R. Boyle, Y. L. Ng, and P. Dewundege, 2003: Year-long, high-resolution, urban airshed modelling: Verification of TAPM predictions of smog and particles in Melbourne, Australia. Atmos. Environ., 37, 1899-1910.

Hurley, P. J., A. Blockley, and K. Rayner, 2001: Verification of a prognostic meteorological and air pollution model for year-long predictions in the Kwinana industrial region of Western Australia. Atmos. Environ., 35, 1871-1880.

Kleinman, L., Y. N. Lee, S. R. Springston, L. Nunnermacker, X. Zhou, R. Brown, K. Hallock, P. Klotz, D. Leahy, J. H. Lee, and L. Newman, 1994: Ozone formation at a rural site in the southeastern United States. J. Geophys. Res., 99, 3469-3482.

Lin, C. H., Y. L. Wu, C. H. Lai, P. H. Lin, H. C. Lai, and P. L. Lin, 2004: Experimental investigation of ozone accumulation overnight during a wintertime ozone episode in south Taiwan. Atmos. Environ., 38, 4267-4278.

Lin, P. L., 2001. Meteorological modeling of air pollution episodes for the Central Air Basin: Simulation and validation. Taiwan-EPA Report No. EPA-89-FA11-03-231.

Ludwig, F. L., J. Y. Jiang, and J. Chen, 1995: Classification of ozone and weather patterns associated with high ozone concentrations in the San Francisco and Monterey Bay areas. Atmos. Environ., 29, 2915-2928.

Neu, U., T. Kunzle, and H. Wanner, 1994: On the relation between ozone storage in the residual layer and daily variation in near-surface ozone concentration - A case study. Boundary Layer Meteor., 69, 221-247.

NRC (National Research Council), 1991: Rethinking the Ozone Problem in Urban and Regional Air Pollution. National Academy Press, Washington, DC.

Salmond, J. A. and I. G. McKendry, 2002: Secondary ozone maxima in a very stable nocturnal boundary layer: Observations from the Lower Fraser Valley, BC. Atmos. Environ., 36, 5771-5782.

Sillman, S., 1999: The relation between ozone, $\mathrm{NO}_{\mathrm{x}}$ and hydrocarbons in urban and polluted rural environments. Atmos. Environ., 33, 1821-1845.

Stauffer, D. R. and N. Seaman, 1994: Multiscale four dimensional data assimilation. J. Appl. Meteorol., 33, 416434.

TEDS-6.03, 2006: Taiwan Emission Data System-Version 6.03. Environmental Protection Administration, Taipei, Taiwan.

Willmott, C. J., S. G. Ackleson, R. E. Davis, J. J. Feddema, K. M. Klink, D. R. Legates, J. O'Donnell, and C. M. Rowe, 1985: Statistics for the evaluation and comparisons of models. J. Geophys. Res., 90, 8995-9005.

Zhang, J. and S. T. Rao, 1999: The role of vertical mixing in the temporal evolution of ground-level ozone concentrations. J. Appl. Meteorol., 38, 1674-1691. 